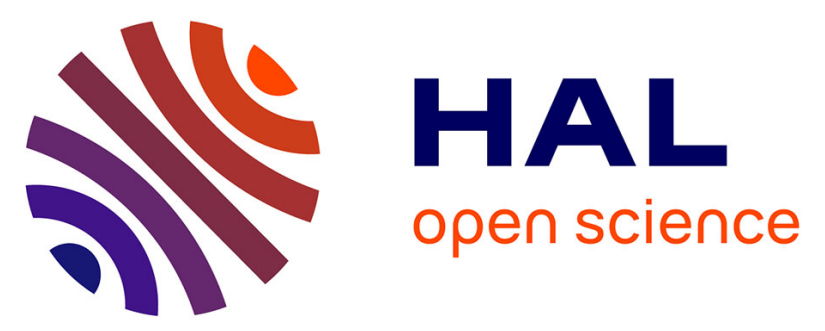

\title{
New coupling between PEEC method and an integro-differential approach for modeling solid conductors in the presence of magnetic-conductive thin plates
}

\author{
Tung Le Duc, Olivier Chadebec, Jean-Michel Guichon, Gérard Meunier
}

\section{To cite this version:}

Tung Le Duc, Olivier Chadebec, Jean-Michel Guichon, Gérard Meunier. New coupling between PEEC method and an integro-differential approach for modeling solid conductors in the presence of magneticconductive thin plates. Eighth International Conference on Computation in Electromagnetics 2011, Apr 2011, Wroclaw, Poland. hal-00591071

\section{HAL Id: hal-00591071 \\ https://hal.science/hal-00591071}

Submitted on 6 May 2011

HAL is a multi-disciplinary open access archive for the deposit and dissemination of scientific research documents, whether they are published or not. The documents may come from teaching and research institutions in France or abroad, or from public or private research centers.
L'archive ouverte pluridisciplinaire HAL, est destinée au dépôt et à la diffusion de documents scientifiques de niveau recherche, publiés ou non, émanant des établissements d'enseignement et de recherche français ou étrangers, des laboratoires publics ou privés. 


\title{
NEW COUPLING BETWEEN PEEC METHOD AND AN INTEGRO-DIFFERENTIAL APPROACH FOR MODELING SOLID CONDUCTORS IN THE PRESENCE OF MAGNETIC-CONDUCTIVE THIN PLATES
}

\author{
T. Le-Duc, O. Chadebec, J-M. Guichon, G. Meunier \\ Grenoble Electrical Engineering Laboratory, Grenoble-INP / Université Joseph Fourier / CNRS \\ $\mathrm{ENSE}^{3}$, BP46, 38402 Grenoble, France \\ Tung.LE-DUC@g2elab.grenoble-inp.fr
}

Keywords: Eddy current, thin plates, PEEC method, integro-differential approach.

\begin{abstract}
In order to introduce magnetic conductive thin plates in quasi-static PEEC method, a coupling with the integrodifferential method is proposed. This coupling enables to take the advantage of each method. The complex conductor geometry is achieved thanks to the PEEC method. The modeling of thin plates is taken into account thanks to an integro-differential one.
\end{abstract}

\section{Introduction}

The PEEC method (Partial Element Equivalent Circuit) is mainly used for the modeling of complex interconnection and can be applied to a large range of devices where the air region is dominant [1], [2]. However, the classical PEEC method does not enable the 3D modeling of conductive and magnetic thin plates. Currently, these kinds of structure are widely present in electric and electronic devices (ferromagnetic shielding) mainly used to reduce radiated magnetic field.

On the other hand, some integral formulations, usually called integro-differential one, have been developed in order to analyze eddy current in thin plate [3], [4]. Like the PEEC method, it does not require the meshing of the air region. A strong coupling between both methods can be accomplished by modeling conductive magnetic regions with an integro-differential approach, while PEEC method allows the modeling the contributions of the inductors fed with alternative currents. This paper presents such formulation.

\section{Coupling principle}

\subsection{Equation for thin plates}

The magnetization $\mathbf{M}$ and the eddy current vector potential $\mathbf{T}_{\mathrm{n}}$ are used in order to model the conductive magnetic thin plate $\left(\mathbf{J}_{\mathrm{c}}=\mathrm{Curl}_{\mathrm{n}}\right)$. In this paper, eddy currents $\mathbf{J}_{\mathrm{c}}$ are assumed to flow tangentially to the shell. Moreover, the assumption of a uniform current distribution across the thickness of the shell is made (i.e. the skin depth is high in comparison with the thickness of the shell). Let us notice that it strongly limites our approach to low frequency problems. As the current is tangential, $\mathbf{T}_{\mathbf{n}}$ is normal to the plate so can be considered as scalar.
The governing equation of $T_{n}$ is given by MaxwellFaraday equations [4]:

$$
\operatorname{Curl}\left(\frac{1}{\sigma} \operatorname{Curl}\left(\mathbf{T}_{\mathrm{n}}\right)\right)=-j \omega \mu_{0} \mu_{\mathrm{r}} \mathbf{H}_{\mathrm{n}}
$$

where $\sigma$ is the conductivity, $\mu_{r}$ is the relative permeability of the material, $\mathbf{H}_{\mathbf{n}}$ is the normal total magnetic field. Considering the relation between the magnetization $\mathbf{M}$ and the magnetic field intensity $\mathbf{H}$, (1) can be rewritten as:

$$
\operatorname{Curl}\left(\frac{1}{\sigma} \operatorname{Curl}\left(\mathbf{T}_{\mathrm{n}}\right)\right)=-j \omega \cdot \mu_{0} \cdot \frac{\mu_{\mathrm{r}}}{\mu_{\mathrm{r}}-1} \mathbf{M}_{\mathrm{n}} .
$$

Let us now consider a conductive magnetic thin plate placed in an inductor field $\mathbf{H}_{0}$. The total magnetic field $\mathbf{H}$ is the sum of $\mathbf{H}_{0}$ and $\mathbf{H}_{\mathrm{m}}$, the reaction of the magnetization and $\mathbf{H}_{c}$, the reaction of the eddy current in thin plate. If $\mathrm{V}$ is the volume of magnetic material and $\Gamma$ its average surface, an integral equation linking the local field to the magnetization and the electric vector potential can be written [3]:

$$
\mathbf{H}=\mathbf{H}_{\mathbf{0}}+\frac{1}{4 \pi} \int_{\mathrm{V}}\left(3 \frac{(\mathbf{M} . \mathbf{r})}{\mathrm{r}^{5}} \mathbf{r}-\frac{\mathbf{M}}{\mathrm{r}^{3}}\right) \mathrm{dV}+\frac{\mathrm{e}}{4 \pi} \int_{\Gamma} \frac{\left(\mathrm{CurlT}_{\mathrm{n}}\right) \times \mathbf{r}}{\mathrm{r}^{3}} \mathrm{~d} \Gamma
$$

where $\mathbf{r}$ is the vector linking the integration point to the point where the field is expressed and $e$ is thickness of plate. These equations have to be discretized. The easiest way is to mesh the thin plate into $n$ triangular prisms elements associated with a constant magnetization (0-order shape functions) a linear variation for eddy current vector potential (constant value of current per element) [3], [4]. For instance, the equation associated to element $\mathrm{k}$ becomes:

$$
\begin{aligned}
\frac{\mathbf{M}_{\mathbf{k}}}{\mu_{\mathrm{r}}-1}= & \frac{1}{4 \pi} \sum_{\mathrm{i}=1}^{\mathrm{n}} \int_{\mathrm{Vi}}\left(3 \frac{\left(\mathbf{M}_{\mathrm{i}} \mathbf{r}\right)}{\mathrm{r}^{5}} \mathrm{r}-\frac{\mathbf{M}_{\mathbf{i}}}{\mathrm{r}^{3}}\right) \mathrm{dV}_{\mathrm{i}}+ \\
& \frac{\mathrm{e}}{4 \pi} \sum_{\mathrm{i}=1}^{\mathrm{n}} \int_{\Gamma_{\mathrm{i}}} \frac{\left(\operatorname{Curl}_{\mathrm{in}}\right) \times \mathbf{r}}{\mathrm{r}^{3}} \mathrm{~d} \Gamma+\mathbf{H}_{0 \mathrm{k}} .
\end{aligned}
$$

Equations (2) and (4) are solved simultaneously to get a linear matrix system if the material is linear. By solving it, $\mathbf{M}$ and $\mathbf{T}_{\mathbf{n}}$ are obtained.

Let's now assume that the inductor field is created by $m$ unknown alternative currents I flowing in $m$ conductors. In a very similar way to the previous one, we can get a linear system of equations. For instance, the equation associated to element $k$ is:

$$
\begin{aligned}
& \frac{\mathbf{M}_{\mathbf{k}}}{\mu_{\mathrm{r}}-1}=\frac{1}{4 \pi} \sum_{\mathrm{i}=1}^{\mathrm{n}} \int_{\mathrm{Vi}_{\mathrm{i}}}\left(3 \frac{\left(\mathbf{M}_{\mathbf{i}} \mathbf{r}\right)}{\mathrm{r}^{5}} \mathrm{r}-\frac{\mathbf{M}_{\mathbf{i}}}{\mathrm{r}^{3}}\right) \mathrm{dV}_{\mathrm{i}}+ \\
& \frac{\mathrm{e}}{4 \pi} \sum_{\mathrm{i}=1}^{\mathrm{n}} \int_{\Gamma_{\mathrm{i}}} \frac{\left(\mathrm{Curl}_{\mathrm{ni}}\right) \times \mathbf{r}}{\mathrm{r}^{3}} \mathrm{~d} \Gamma_{\mathrm{i}}+\frac{1}{4 \pi} \sum_{\mathrm{j}=\mathrm{i}}^{\mathrm{m}} \int_{\mathrm{V}_{\text {cond }-j}} \frac{\mathbf{d l} \times \mathbf{r}}{\mathrm{r}^{3}} \mathrm{I}_{\mathrm{j}} \mathrm{dV}_{\mathrm{j}} .
\end{aligned}
$$


The third integral term corresponds to the Biot and Savart's law integrated on each conductor volume

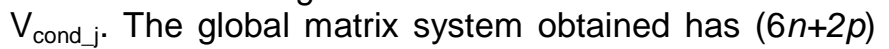
equations (the mesh is being composed of $p$ nodes) and $6 n+2 p+2 m$ unknowns (plus $m$ complex currents).

\subsection{Inductive PEEC method}

Let us consider $m$ volume conductors fed with alternative sources placed in a surrounding air region without any magnetic materials. The well-known PEEC method is particularly reliable to solve this kind of problem. It is based on the determination of partial voltage generated on each conductor by electromagnetic sources. To compute these voltages volume integration on the conductor of the magnetic vector potential created by all the others conductor is provided. For instance, for the conductor $\mathrm{k}$, the expression is [1]:

$$
\mathrm{U}_{\mathrm{k}_{-} \text {cond }}=\frac{\mu_{0}}{4 \pi} \frac{\mathrm{j} \omega}{\mathrm{s}_{\mathrm{k}}} \int_{\mathrm{V}_{\mathrm{k}}}\left(\sum_{\mathrm{i}=1}^{\mathrm{m}} \frac{\mathrm{I}_{\mathrm{i}}}{\mathrm{s}_{\mathrm{i}}} \int_{\mathrm{V}_{\mathrm{i}}}^{1} \frac{1}{\mathrm{r}} \mathrm{d} \mathbf{V}_{\mathrm{i}}\right) \mathrm{d} \mathbf{V}_{\mathrm{k}} .
$$

where $\omega$ is the angular frequency and $S_{i}$ is the section of the $i$-th conductor. This equation links partial voltages of conductors to currents flowing in them. If we write this equation for all conductors, we get a matrix system known as impedance matrix system. By combing these electromagnetic equations with the circuit ones representative of the conductors wiring and adding ohmic effect, it is possible to get a simplified system representative of the device which can be easily coupled with a standard circuit simulator. This inductive PEEC method has already shown is efficiency for the modeling of complex conductor geometries in comparison with FEM.

Let us now consider that conductive magnetic thin plate is present in the surrounding air region. Equation (6) has to be modified by taking into account the influence of the field created by the plate. A new voltage has to be added to the previous one, for instance:

$$
\begin{aligned}
\mathrm{U}_{\mathrm{k}_{-} \text {cond }}= & \frac{\mu_{0}}{4 \pi} \frac{\mathrm{j} \omega}{\mathrm{s}_{\mathrm{k}}} \int_{\mathrm{V}_{\mathrm{k}}}\left(\sum_{\mathrm{i}=1}^{\mathrm{m}} \frac{\mathrm{I}_{\mathrm{i}}}{\mathrm{s}_{\mathrm{i}}} \int_{\mathrm{V}_{\mathrm{i}}} \frac{1}{\mathrm{r}} \mathrm{d} \mathbf{V}_{\mathrm{i}}+\sum_{\mathrm{i}=1}^{\mathrm{n}} \int_{\mathrm{V}_{\mathrm{i}}} \frac{\mathbf{M}_{\mathrm{i}} \times \mathbf{r}_{\mathrm{r}}}{\mathrm{r}^{3}} \mathrm{~d} \mathbf{V}_{\mathrm{i}}+\right. \\
& \text { e. } \left.\sum_{\mathrm{i}=1}^{\mathrm{n}} \int_{\Gamma_{\mathrm{i}}} \frac{\mathrm{Curl}_{\mathbf{T}_{\mathrm{ni}}}}{\mathrm{r}} \mathrm{d} \Gamma_{\mathrm{i}}\right) \cdot \mathrm{d} \mathbf{V}_{\mathrm{k}} .
\end{aligned}
$$

Finally, equations (2), (5) and (7) are brought together in a global square $(6 n+2 p+2 m) \times(6 n+2 p+2 m)$ matrix system. By taking into account circuit equations, it is possible to reduce global equation to get a lighter system with $(6 n+2 p+2 q)$ unknowns (if we consider that there are $q$ independent circuits). This equation is solved to get magnetizations, eddy current in thin plate and currents in conductors.

\section{Numerical Examples}

In this example, a single conductor is considered with a thin plate $\left(\mu_{r}=50\right.$, linear and $\left.\sigma=9.6 \mathrm{E}+6 \mathrm{~S} / \mathrm{m}\right)$ placed close to it. The conductor is fed by a voltage source (1V,
$50 \mathrm{~Hz}$ ). Our coupling is compared with results given by FEM in Flux software [5]. We focus on the computed eddy current distribution and loss in the plate (Figure 1 and table 1). Whereas the convergence is quickly reached with our coupling, the problem needs a very fine mesh to be accurately solved with FEM. We can see a small difference between both computed values. Results provided by our coupling are very encouraging, the convergence being reached with a very few number of elements (around 600). Of course, the obtained matrix is fully dense, but the computation time is divided per ten in comparison with FEM.

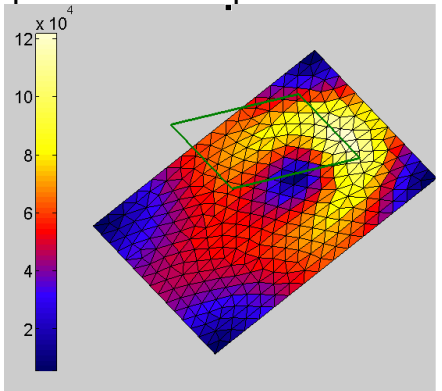

Our Coupling method

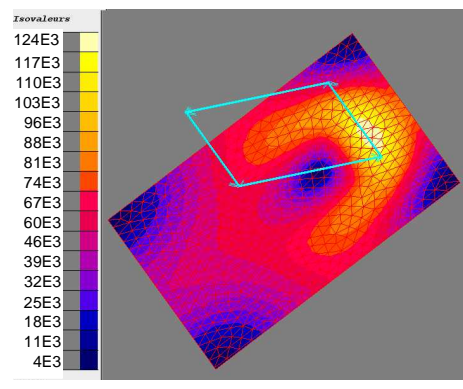

FEM method
Figure 1: Eddy current in thin plate computed by FEM and our coupling

\begin{tabular}{|c|c|c|}
\hline Method & Loss in plate (W) & Diff. (\%) \\
\hline $\begin{array}{c}\text { FEM with 1.400.000 } \\
\text { elements }\end{array}$ & $10.9 \mathrm{E}-3$ & reference \\
\hline $\begin{array}{c}\text { Our coupling with } \\
600 \text { elements }\end{array}$ & $10.7 \mathrm{E}-3$ & $1,7 \%$ \\
\hline
\end{tabular}

Table 1: Loss in thin plate (W) obtained

\section{Conclusions}

In this paper, we have presented a coupling between PEEC and an integro-differential method in order to introduce any shape of magnetic-conductive thin plates in PEEC method. This new coupling can be very fast and accurate. In further works, formulations enabling smaller skin depth will be investigated.

\section{References}

[1] A.E. Ruehli."Equivalent circuit models for three dimensional multiconductor systems", IEEE Trans. Microwave Theory and Tech, vol. 22, no.3, (1974).

[2] E.Clavel, J.Roudet, A.Foggia."Electrical Modeling of Transformer Connecting Bars", IEEE Trans. Magn., vol. 38, No. 2, (2002).

[3] A. Kalimov, F. Klos, B.Langenbeck and G. Moritz "Dynamic Processes in Laminated Magnets: Simulation and Comparison with Experimental Results", IEEE Trans. Appl. Supperconduct., vol.12, no.1, pp. 98-101, (2002).

[4] S.J.Salon, B.Mathewson and S.Uda. "An IntergroDifferential approach to eddy currents in thin plates", IEEE Trans. Magn., vol.19, no.6, pp. 24052408, (1983).

[5] Flux Cedrat. Meylan, France: www.cedrat.com 